\title{
CpG site methylation in CRYAA promoter affect transcription factor Sp1 binding in human lens epithelial cells
}

\author{
Xin Liu ${ }^{1,2,3 \dagger}$, Peng Zhou, ${ }^{4,5 \dagger}$, Fan Fan ${ }^{1,2,3}$, Dan $\mathrm{Li}^{3}$, Jihong $\mathrm{Wu}^{1,3}, \mathrm{Yi} \mathrm{Lu}^{1,2,3}$ and Yi Luo ${ }^{1,2,3^{*}}$
}

\begin{abstract}
Background: Age-related cataract (ARC) is the leading cause of visual impairment worldwide, and a-crystallin (CRYAA) is the predominant structural protein involved in the maintenance of lens clarity and refractive properties. We previously demonstrated that CRYAA genes undergo epigenetic repression in the lens epithelia in ARC. We further analyze the underlying mechanism in the current study.

Methods: The transcription factor binding sites of the CpG island of CRYAA promoter were predicted by TESS website. An electrophoretic mobility shift assay (EMSA) was used to analyze the impact of the methylation of CpG sites on transcription factors. Human lens epithelial B-3 (HLE B-3) Cells were treated with demethylation agent zebularine in the concentrations of 0 (PBS as control), $10 \mu \mathrm{M}, 20 \mu \mathrm{M}, 50 \mu \mathrm{M}, 100 \mu \mathrm{M}$ and $200 \mu \mathrm{M}$, respectively. After treatment in the above concentrations for $24 \mathrm{~h}, 48 \mathrm{~h}$ and $72 \mathrm{~h}$, respectively, CRYAA mRNA expression levels were detected by Quantitative Real-Time RT-PCR.

Results: The methylation of the CpG site of the CRYAA promoter decreased the DNA-binding capacity of transcription factor Sp1. Zebularine increased CRYAA expression in HLE B-3 Cells in a dose- dependent and time- dependent pattern.

Conclusions: The evidence presented suggests that the methylation of the CPG sites of the CRYAA promotor directly affect Sp1 binding, leading to down expression of CRYAA in human lens epithelial cells. Zebularine treatment could restore CRYAA expression in a dose- dependent and time- dependent pattern.
\end{abstract}

Keywords: DNA methylation, CRYAA, Transcription factor Sp1, Human lens epithelial cells, Zebularine

\section{Background}

Age-related cataract (ARC) is the leading cause of visual impairment among older adults [1, 2]. It is widely accepted that senescence, heredity, and environment are the major contributing factors in ARC and that oxidative stress plays an important role in cataractogenesis [3, 4]. However, the precise mechanism of ARC remains to be further elucidated.

Lens crystallins are the predominant structural proteins involved in the maintenance of lens clarity and refractive

\footnotetext{
* Correspondence: yeeluo1106@163.com

${ }^{\dagger}$ Equal contributors

'Department of Ophthalmology, Eye and ENT Hospital of Fudan University, 83 FenYang Road, Shanghai 200031, People's Republic of China

${ }^{2}$ Key Laboratory of Myopia, Ministry of Health, 83 FenYang Road, Shanghai 200031, People's Republic of China

Full list of author information is available at the end of the article
}

properties [5, 6]. $\alpha$-crystallins constitute $35 \%$ of all crystallins [7]. Its molecular chaperone-like activity protects other crystallins against thermal-induced inactivation or aggregation and allows the lens to resist the aginginduced deterioration of proteins [8]; therefore it is thought to be critical for maintaining lens transparency. Our previous studies have shown, for the first time, that DNA methylation regulates gene expression in lens epithelial cells $[9,10]$. CRYAA undergoes epigenetic repression in the lens epithelia in nuclear ARC [11]. However, the mechanism of CRYAA DNA methylation remains to be explored.

Epigenetic modifications are post-transcriptional, reversible, and hereditable events that do not alter the genetic sequence. The epigenetic regulation of gene expression mainly includes DNA methylation, histone 
modification, and non-coding RNA [12]. DNA methylation, mostly in the form of $5^{\prime}$-methylcytosine in CpG dinucleotides in the presence of DNA methyltransferases (DNMTs), often acts as a transcriptional repressor [13]. It can directly prevent the binding of transcription factors or act through interactions with methyl-CpGbinding domain (MBD) proteins and histone deacetylases (HDACs), resulting in gene silencing [14].

In the present study, we analyzed the impact of the methylation of CpG sites on transcription factors to explore the underlying mechanism of the down regulation of CRYAA in nuclear ARC. We also investigated the effect of DNA-demethylating agent Zebularine on the expression of CRYAA.

\section{Methods}

All procedures were performed in accordance with the tenets of the Declaration of Helsinki. The institutional review board of the Eye and ENT Hospital of Fudan University approved our use of cultured human lens epithelial cells.

\section{Human lens epithelium B-3 (HLE B-3) cell culture}

HLE B-3 cells were obtained from American Type Culture Collection (ATCC; Rockville, MD, USA) and cultured in Eagle's minimum essential medium (Gibco-BRL, Grand Island, NY, USA) with $20 \%$ FBS, $100 \mathrm{U} / \mathrm{ml}$ penicillin, and $100 \mathrm{mg} / \mathrm{ml}$ streptomycin at $37{ }^{\circ} \mathrm{C}$ in a humidified $5 \% \mathrm{CO}_{2}$ atmosphere.

\section{In silico analysis}

The transcription factor binding sites of the CpG island of CRYAA promoter were predicted by TESS website (http://www.cbil.upenn.edu/cgi-bin/tess/tess) as described before [15].

\section{Electrophoretic Mobility Shift Assay (EMSA)}

EMSA was conducted as described previously, with minor changes $[15,16]$. Nuclear proteins were extracted from HLE B3 cells using NE-PER nuclear and cytoplasmic extraction reagents (Pierce Biotechnology, Rockford, IL, USA). Methylated and wild-type oligonucleotides, were purchased from Shenggong Technologies, Inc. (China). These included the wildtype SP-1 consensus binding sequence of the CRYAA promoter (5' -GGCTGGGCGTCCA-3') and the methylated Sp1 consensus binding sequence (5' -GG

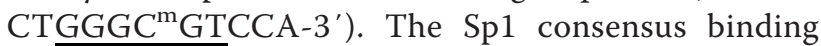
site is underlined. All listed oligonucleotides included antisense oligonucleotide strands. In methylated oligonucleotides, the antisense oligonucleotide strands were methylated at the cytosine corresponding to that of the sense strand. EMSA probes were synthesized as double strands after pair annealing and 3 '-end-labeled with biotin (Invitrogen). Unlabeled oligonucleotides with identical sequences were used as competitors. The EMSA was performed using the LightShift Chemiluminescent EMSA kit (Pierce Biotechnology), following the manufacturer's protocol. For supershift experiments, Sp1 antibody (Abcam) was added to the reaction solution $30 \mathrm{~min}$ prior to the addition of the probes. The densities (total gray) of the bands were calculated using Glyko Bandscan 5.0 software (ProZyme, Hayward, CA, USA).

\section{Zebularine treatment}

A demethylating agent, 1-( $\beta$-D-ribofuranosyl)-1,2-dihydropyrimidin-2-one, or zebularine (Sigma), was used to investigate its effect on the expression of HLE B-3 cells as described previously [17]. Cells were plated at a density of $2^{*} 10^{5}$ per well in six-well plates $24 \mathrm{~h}$ before treatment. Cells were treated with 0 (PBS as control), $10 \mu \mathrm{M}, 20 \mu \mathrm{M}$, $50 \mu \mathrm{M}, 100 \mu \mathrm{M}$ and $200 \mu \mathrm{M}$ Zebularine, respectively. After treatment in the above concentrations for $24 \mathrm{~h}, 48 \mathrm{~h}$ and $72 \mathrm{~h}$, respectively, the cells were harvested.

\section{Quantitative real-time RT-PCR}

Total RNA was isolated from HLE B-3 cells after Zebularine treatment using RNeasy Mini Kit (Qiagen, Valencia, CA, USA) according to the manufacturer's instructions. A total of $1 \mu \mathrm{g}$ total RNA extracted was reverse transcribed with the PrimeScript ${ }^{\mathrm{Tm}} \mathrm{RT}$ Master Mix (Takara Bio, Inc., Shiga, Japan) in accordance with the manufacturer's protocol. [18] CRYAA mRNA expression were detected using a SYBR Green detection kit (SYBR Premix Ex Taq; Takara, Osaka, Japan) as described previously [19]. $\beta$-actin was used as an internal control. The primers used in qRT-PCR were as follows: (a) Gene "Homo sapiens crystallin alpha A (CRYAA), mRNA", the NCBI Reference Sequence is NM_000394.3"; Forward primer "GAAGGTGCAGGACGACTTTG" is located from 273 nt to 292 nt of the NM_000394.3 sequence; Reverse primer "CAGAAGGTCAGCATGCCATC" is located from 437 nt to 428 nt of the NM_000394.3 sequence. (b) Gene "Homo sapiens ACTB actin, beta, mRNA", the NCBI Reference Sequence is NM_001101.3"; Forward primer " CAACTCCATCATGAAGTGTGACG” is located from 921 nt to 943 nt of the NM_001101.3 sequence; Reverse primer "ACTCGTCATACTCCTGCTTGC" is located from 1177 nt to 1157 nt of the NM_001101.3 sequence. qRT-PCR reactions were performed with a ViiA 7 Real-Time PCR System (Life Technologies, Pleasanton, CA). Relative fold changes in CRYAA mRNA expression were determined by calculating $2^{-\Delta \Delta C T}$ with ViiA 7 Software (Life Technologies). All qRT-PCR experiments were performed for three times, with biological triplicates in each experiment. 


\section{Statistical analysis}

The results of the experiments are expressed as means \pm SD. A student's $t$-test or the Mann-Whitney test was used to compare quantitative data between two groups. A value of $P<0.05$ was considered significant.

\section{Results}

\section{Transcription factor binding sites prediction}

Our previous study demonstrated that $\mathrm{CpG}$ sites in the CpG island of CRYAA promoter were hypermethylated in the lens epithelia of nuclear ARC cases versus agematched controls [11]. The sequence around the CpG site, which displayed the most significant differences in methylation between nuclear ARC cases and controls, was analyzed for transcription factor binding prediction via TESS website. Several transcription factor-binding sites were predicted in the sequence (Fig. 1a). The most frequent predicted transcription factor was Sp1. A selected sequence, which mainly bound to $\mathrm{Sp} 1$, was chosen for further study (Fig. 1b). If this sequence was mutated, no transcription factor binding was found (Fig. 1c). As the effect of methylation on transcription factor could not be predicted by the website, we used the model of mutated sequence to predict the effect of change of the CpG site to the binding of transcription factor. According to the prediction results, we hypothesized that transcription factor binding would be affected after methylation of the CpG site. We used EMSA to further confirm our prediction and hypothesis.

CpG methylation of CRYAA promoter decreases the DNAbinding capacity of transcription factor Sp1

EMSA was performed to determine whether the methylation of the $\mathrm{CpG}$ sites of the CRYAA promoter influences the binding of transcription factor Sp1 to its consensus binding sequence. A labeled wild-type probe containing the Sp1 consensus binding sequence (GGGCGT) of the CRYAA promoter was used to test Sp1 binding. The incubation of HLE B-3 nuclear extracts with a wild-type Sp1 probe revealed a pattern of shifted bands representing Sp1 binding activity. HLE B-3 nuclear extracts were able to bind the wild-type Sp1 probe (lane 1), while the binding capacity significantly decreased when incubated with a methylated probe (lane 4 and 8). The unlabeled wild-type Sp1 probe can sufficiently compete with the labeled wild-type probe (lane 2), while the unlabeled methylated probe could not compete (lane 3). When Sp1 antibody was added to the incubation mixture, Sp1-specific binding was demonstrated via the decreased intensity of the Sp1 bands, as well as by a supershift seen in lane 7 (Fig. 2). This result suggests that the hypermethylation of the $\mathrm{CpG}$ sites of

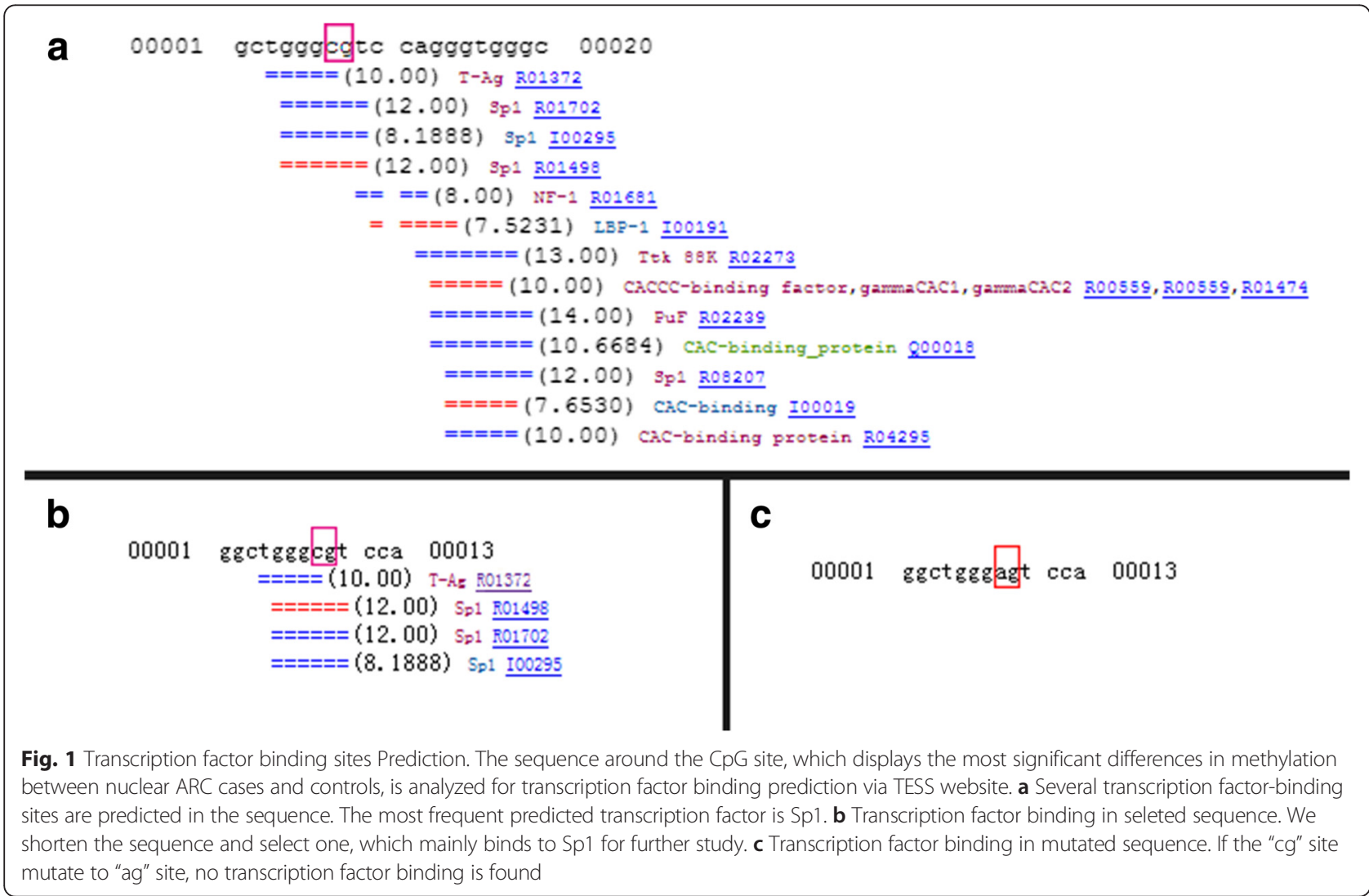




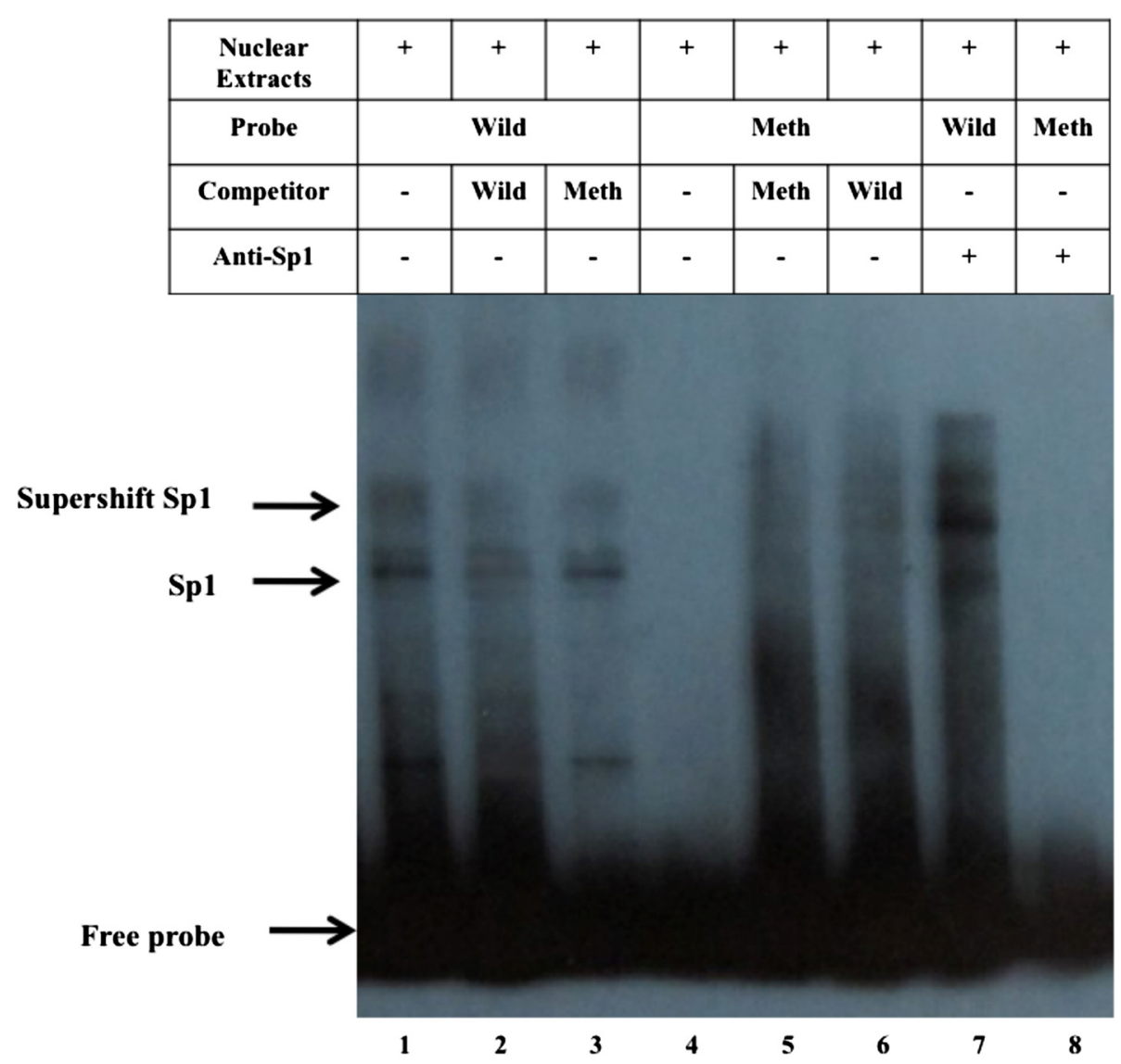

Fig. 2 CpG methylation of CRYAA promoter decreases the DNA-binding capacity of transcription factor SP-1. EMSA experiments show the specific binding of Sp1 to the binding sequence of the CRYAA promoter. Lane 1: biotin-labeled wild-type Sp1 probe incubated with HLE B-3 nuclear extracts. Sp1 binding is depicted by arrows on the left of the figures. Lane 2: excess unlabeled wild-type competitor (1:100) competes for binding with the labeled probe. Lane 3: unlabeled methylated competitor (1:100) does not compete with the labeled probe. Lane 4: labeled methylated probe incubates with nuclear extracts. No binding was shown. Lanes 5 and 6: excess unlabeled wild-type and methylated competitors (1:100) were added, respectively. No binding of Sp1 was shown. Lane 7 shows anti-Sp1 supershift. Anti-Sp1 antibody is added to nuclear extracts incubating with a wild-type probe. Lane 8 shows no binding of Sp1. Anti-Sp1 antibody is added to nuclear extracts incubating with a methylated probe

the CRYAA promoter decreases the DNA-binding capacity of transcription factor Sp1.

\section{Demethylation using zebularine increased CRYAA expression in a dose- dependent and time- dependent pattern in HLE B-3 cells}

We analyzed treatment of demethylation agent zebularine on CRYAA mRNA expression in lens epithelial cells. Our results indicated that zebularine increased CRYAA mRNA expression in a dose-dependent pattern. As the concentration of zebularine increased from $10 \mu \mathrm{M}$ to $200 \mu \mathrm{M}$, the CRYAA mRNA level increased to 4.5 fold of untreated controls after zebularine treatment for $24 \mathrm{~h}, 25.6$ fold for $48 \mathrm{~h}$ and 42.0 fold for $72 \mathrm{~h}(P<0.05)$ (Fig. 3a). Zebularine also increased CRYAA mRNA expression in a timedependent pattern. After 24 to $72 \mathrm{~h}$ with zebularine treatment of different concentrations, the CRYAA mRNA expression level increased to 3.4 fold of the control level in $10 \mu \mathrm{M}$ concentration, 15.6 fold in $20 \mu \mathrm{M}$,
29.1 fold in $50 \mu \mathrm{M}, 78.8$ fold in $100 \mu \mathrm{M}$ and 147.3 fold in $200 \mu \mathrm{M}(P<0.05)$ (Fig. 3b). These results suggested that demethylation could lead to upregulation of CRYAA expression in a dose- dependent and timedependent pattern (Additional files 1, 2, 3 and 4).

\section{Discussion}

Diverse DNA methylation patterns have recently been discovered in many ocular diseases, including glaucoma [20], age-related macular degeneration (AMD) [21], retinoblastoma [22-25], uveal melanoma [26-29], and cataract $[11,30]$. Our previous work demonstrated, for the first time, that DNA methylation down-regulates CRYAA gene expression in lens epithelial cells in nuclear ARC [9-11]. However, little is known about the precise mechanism of DNA methylation of CRYAA. In this study, we showed that in lens epithelial cells, the methylation of the CpG site of the CRYAA promoter decreased the DNA-binding capacity of transcription factor Sp1. 

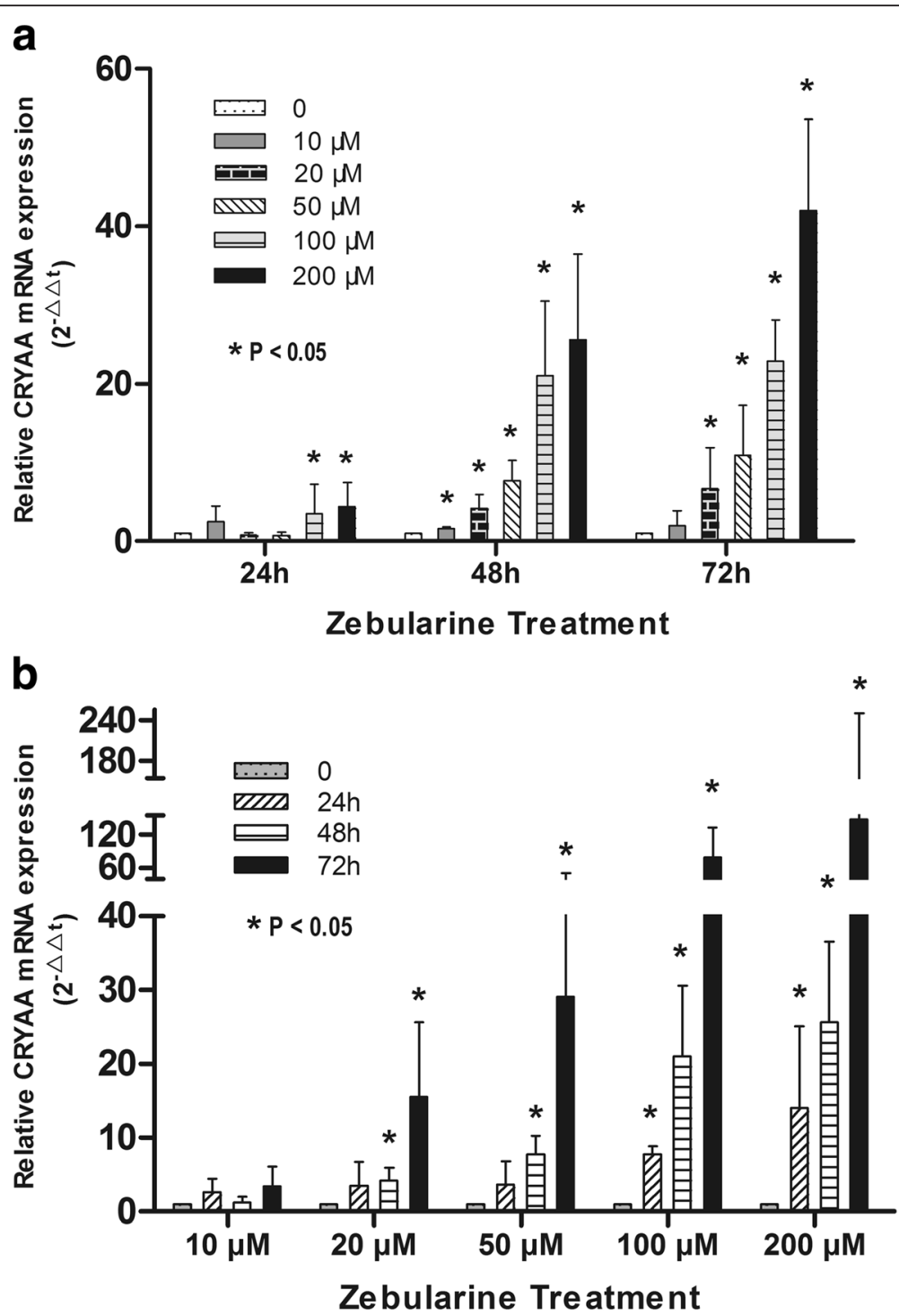

Fig. 3 Demethylation agent Zebularine increased CRYAA mRNA expression in HLE B-3 cells detected by Real time qRT-PCR. A. Zebularine increased CRYAA mRNA expression in a dose-dependent pattern. As the concentration of zebularine increased from $10 \mu \mathrm{M}$ to $200 \mu \mathrm{M}$, the CRYAA mRNA level increased to 4.5 fold of untreated controls after zebularine treatment for $24 \mathrm{~h}, 25.6$ fold for $48 \mathrm{~h}$ and 42.0 fold for $72 \mathrm{~h}$. B. Zebularine also increased CRYAA mRNA expression in a time-dependent pattern. After 24 to $72 \mathrm{~h}$ with zebularine treatment of different concentrations, the CRYAA mRNA expression level increased to 3.4 fold of the control level in $10 \mu \mathrm{M}$ concentration, 15.6 fold in $20 \mu \mathrm{M}, 29.1$ fold in $50 \mu \mathrm{M}, 78.8$ fold in $100 \mu \mathrm{M}$ and 147.3 fold in $200 \mu \mathrm{M}$. ${ }^{*} P<0.05$. The error bars represent standard deviation of the mean of 3 experiments

Treatment with the DNA-demethylating agent Zebularine increased CRYAA expression in a dose- dependent and time- dependent pattern. Overall, these findings suggest that the methylation of the CpG sites of the CRYAA promotor directly affects transcription factor binding and is related to the epigenetic repression in nuclear ARC lenses. We have demonstrated the underlying mechanism of the DNA methylation of CRYAA in HLE B-3 cells.

DNA methylation may be an important mechanism in the pathogenesis and progression of cataract. Critical enzymes involved in DNA methylation, such as DNMT1 and $\mathrm{MeCP} 2$, were found in human lens epithelial cells
$[9,10]$. The down-regulation of CRYAA via the hypermethylation of $\mathrm{CPG}$ islands in its promoter was found in nuclear ARC cases [11]. It was also reported to be related to the earlier onset of dark nucleus in highly myopic patients [31], as well as nuclear cataract formation after pars plana vitrectomy [32]. It is established that the localized reduction of antioxidative capacity in the nuclear region of the lens results in increasing numbers of denatured proteins [3]. Down-regulation via the promoter hypermethylation of CRYAA reduces the expression of chaperones, which are able to bind to these denatured proteins and thus preserve the transparency 
of the lens [6]. This may accelerate the oxidative modification of proteins in the nucleus, resulting in the pathogenesis of nuclear cataract [31]. The dysfunction of Nrf2-dependent antioxidant protection via endoplasmicreticulum-associated degradation and redox- balance alteration in the lens due to the demethylation of the CpG islands in the Keap1 promoter is linked to diabetic cataracts and ARCs in both human lens epithelial cells and animal models [30, 33, 34]. The DNA hypermethylation of the promoter region of the DNA repair gene MGMT may regulate the down-expression of the gene and be involved in the development of ARC [35]. In cortical ARC, the loss of functional OGG1 via the base excision repair pathway results in oxidative DNA base damage [36, 37]. Reduced OGG1 expression was correlated with the hypermethylation of a $\mathrm{CpG}$ island of OGG1 in ARC lenses [38]. Pseudoexfoliation syndrome (PEX)-complicated cataracts also underwent epigenetic regulation. The susceptible PEX gene LOXL1 was hypermethylated in its promoter region and was down- regulated on the mRNA and protein level in Uighur PEX cataract patients [39]. Together, these results suggest that many critical genes related to antioxidative capacity and DNA repair underwent epigenetic repression during the pathogenesis of ARC. In this study, we demonstrated that demethylation treatment with Zebularine increased CRYAA expression level in a dose- dependent and timedependent pattern.

The methylation status of critical CpG sites often conversely correlates with the transcriptional activity of promoters. Two modes exist that explain how the methylation of CpG sites interferes with transcription. Methylated CpG sites can directly interfere with the binding of transcription factors to their recognition sites or facilitate the binding of a family of methyl-binding proteins to their cognate DNA sequences [40]. In this study, we demonstrated that the methylation of the CpG sites of the CRYAA promoter could directly interfere with the binding of transcription factor $\mathrm{Sp} 1$ to its recognition elements, which is related to gene repression. Our results were consistent with the previous findings. Clark SJ et al. [41] discovered that ${ }^{\mathrm{m}} \mathrm{Cp}{ }^{\mathrm{m}} \mathrm{CpG}$ methylation could have a biological function in preventing $\mathrm{Sp} 1$ binding, thereby contributing to the subsequent abnormal methylation of $\mathrm{CpG}$ islands often observed in tumor cells. Zhu WG et al. [16] demonstrated that hypermethylation around consensus Sp1-binding sites may directly reduce $\mathrm{Sp} 1 / \mathrm{Sp} 3$ binding, leading to reduced $\mathrm{p} 21^{\mathrm{Cip} 1}$ expression in response to depsipeptide treatment. Zelko et al. [42] found that CpG methylation attenuates Sp1 and Sp3 binding to the human extracellular superoxide dismutase promoter and regulates its cellspecific expression. Douet et al. [43] provided the first direct evidence that $\mathrm{CpG}$ methylation of the $A b c c 6$ proximal promoter region regulates the binding of transcription factor $\mathrm{Sp} 1$ and participates in tissuespecific expression control in mice. Li et al. [44] demonstrated that treatment with the demethylation agent 5-aza-2'-deoxycytidine markedly enhanced the binding affinity of $\mathrm{Sp} 1 / \mathrm{Sp} 3$ to the promoter region and restored the expression of CIDE-A gene in cells. This treatment was also effective in the restoration of the binding of Sp1 to the promoter, as well as Keap1 expression, in an A549 cell line [45]. In the current study, the excess wild-type competitors did not completely competed away the binding of SP1 in Lane 2 . HLE B-3 nuclear extracts were able to bind both the labeled and unlabeled wild-type Sp1 probe. When excess unlabeled wild-type Sp1 probe (100 fold) was used to compete with the labeled wild-type probe, most Sp1 and other transcription factors binded to the unlabeled wild-type $\mathrm{Sp} 1$ probe. However, the binding capacity of $\mathrm{Sp} 1$ and the wild-type probe was high. The low concentration of labeled wild-type

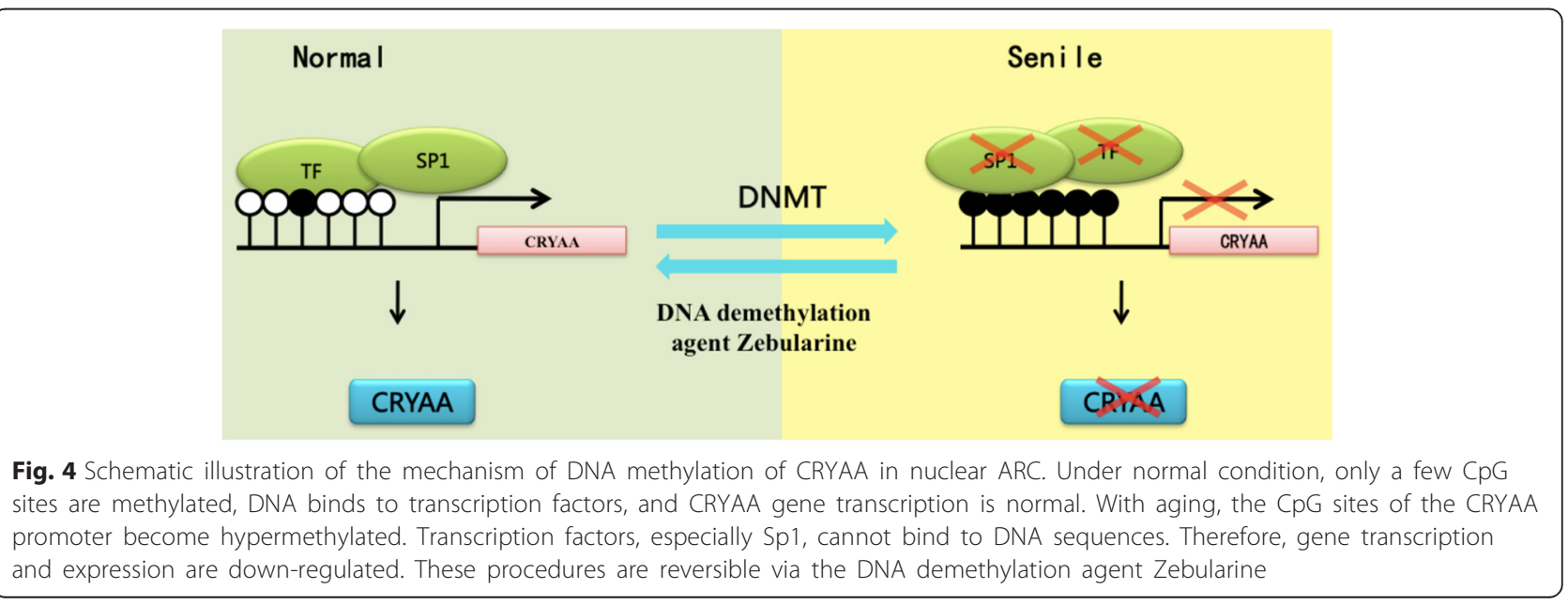


probe could still bind to some SP1. The result indicated that the binding capacity of the low concentration of wild-type probe with SP1 was higher than the normal concentration of the methylated probe. It further confirmed that the methylation of the $\mathrm{CpG}$ sites of the CRYAA promoter influences the binding capacity of transcription factor Sp1. These results indicate that $\mathrm{CpG}$ methylation plays an important role in establishing and maintaining the tissue- and cellspecific transcription of genes through the direct regulation of $\mathrm{Sp} 1$ binding.

In this study, we did not investigate the possibility of de novo DNA methylation occurring. Further studies should focus on the pathway that affects DNA methylation. Performing bisulphite analysis to analyze the methylation status of the CpG sites around this SP1 binding site will further increase the significance of the study.

\section{Conclusion}

The present study demonstrated that the methylation of the CpG site of the CRYAA promoter decreased the DNA-binding capacity of transcription factor Sp1. Treatment with the DNA-demethylating agent Zebularine increased CRYAA expression in HLE B-3 Cells in a dosedependent and time- dependent pattern. Overall, these findings suggest that the methylation of the $\mathrm{CpG}$ sites of the CRYAA promotor directly affect $\mathrm{Sp} 1$ binding, leading to epigenetic repression in nuclear ARC lenses (Fig. 4). The present study provides some basis for further understanding of the mechanism evolving the epigenetic pathogenesis of nuclear ARC, and it is promising for exploration of novel cataract therapies.

\section{Additional files}

Additional file 1: Row data of qRT-PCR for CRYAA after Zebularine treatment, Experiment 1, Part 1. CRYAA mRNA expression were detected using a SYBR Green detection kit. $\beta$-actin was used as an internal control. qRT-PCR reactions were performed with a ViiA 7 Real-Time PCR System. All qRT-PCR experiments were performed for three times, with biological triplicates in each experiment. It is the rata data of part 1 of the first experiment. (XLS $2430 \mathrm{~kb}$ )

Additional file 2: Row data of qRT-PCR for CRYAA after Zebularine treatment, Experiment 1, Part 2. It is the rata data of part 2 of the first experiment described above. (XLS $2440 \mathrm{~kb}$ )

Additional file 3: Row data of qRT-PCR for CRYAA after Zebularine treatment, Experiment 2. It is the rata data of the second experiment described above. (XLS $2431 \mathrm{~kb}$ )

Additional file 4: Row data of qRT-PCR for CRYAA after Zebularine treatment, Experiment 3. It is the rata data of the third experiment described above. (XLS $2630 \mathrm{~kb}$ )

\section{Acknowledgements}

We would like to acknowledge Dr. Zhang Shujie and Dr. Hu Fangyuan, from Eye and ENT hospital of Fudan University, for their help in study design and qRT-PCR experiment.

\section{Funding}

This study was supported by grants from the National Natural Science Foundation of China (81371002 and 81200669).

\section{Availability of data and materials}

The dataset supporting the conclusions of this article is available in the [row data] repository uploaded as supplementary materials.

\section{Authors' contributions}

$\mathrm{XL}$ performed the EMSA and $\mathrm{qRT}-\mathrm{PCR}$ experiments, participated in the design of the study and drafted the manuscript. PZ participated in the conception and design of the study and the critical revision of the manuscript. FF performed the data collection and analysis. DL and JW contributed the cell culture and Zebularine treatment for the study. Yi Lu helped to revise the statistical analysis and helped to revise the manuscript. Yi Luo obtained funding for the study, participated in the study design, and helped to revise the manuscript. All authors read and approved the final version of the manuscript. The first two authors ( XL and $\mathrm{PZ}$ ) contributed equally to this work and should be considered as co- first authors. This study was presented at the 2015 Association for Research in Vision and Ophthalmology (ARVO) Annual Meeting, Denver, Colorado, USA, May 7th, 2015.

\section{Competing interests}

The authors declare that they have no competing interests.

\section{Consent for publication}

Not applicable. This research does not involve individual participants.

\section{Ethics approval and consent to participate}

All procedures were performed in accordance with the tenets of the Declaration of Helsinki. The institutional review board of the Eye and ENT Hospital of Fudan University approved our use of cultured human lens epithelial cells.

\section{Author details}

${ }^{1}$ Department of Ophthalmology, Eye and ENT Hospital of Fudan University, 83 FenYang Road, Shanghai 200031, People's Republic of China. ${ }^{2}$ Key Laboratory of Myopia, Ministry of Health, 83 FenYang Road, Shanghai 200031, People's Republic of China. ${ }^{3}$ Shanghai Key Laboratory of Visual Impairment and Restoration, Fudan University, 83 FenYang Road, Shanghai 200031, People's Republic of China. ${ }^{4}$ Department of Ophthalmology, Parkway Health, Specialty and Inpatient Center (Luwan), 170 DanShui Road, Floor 3, Shanghai 200020, People's Republic of China. ${ }^{5}$ Hong Qiao Medical Center, 2258 HongQiao Road, Shanghai 200033, People's Republic of China.

Received: 29 December 2015 Accepted: 28 July 2016

Published online: 09 August 2016

\section{References}

1. Richter GM, Chung J, Azen SP, Varma R, Los Angeles Latino Eye Study G. Prevalence of visually significant cataract and factors associated with unmet need for cataract surgery: Los Angeles Latino Eye study. Ophthalmology. 2009;1 16(12):2327-35.

2. Resnikoff S, Pascolini D, Etya'ale D, Kocur I, Pararajasegaram R, Pokharel GP, Mariotti SP. Global data on visual impairment in the year 2002. Bull World Health Organ. 2004;82(11):844-51.

3. Michael R, Bron AJ. The ageing lens and cataract: a model of normal and pathological ageing. Philos Trans R Soc Lond B Biol Sci. 2011;366(1568):1278-92.

4. Sacca SC, Bolognesi C, Battistella A, Bagnis A, Izzotti A. Gene-environment interactions in ocular diseases. Mutat Res. 2009:667(1-2):98-117.

5. Andley UP. Effects of alpha-crystallin on lens cell function and cataract pathology. Curr Mol Med. 2009;9(7):887-92.

6. Chen Y, Yi L, Yan GQ, Jang YX, Fang YW, Wu XH, Zhou XW, Wei LM. Decreased chaperone activity of alpha-crystallins in naphthaleneinduced cataract possibly results from C-terminal truncation. J Int Med Res. 2010;38(3):1016-28.

7. Thampi P, Hassan A, Smith JB, Abraham EC. Enhanced C-terminal truncation of alphaA- and alphaB-crystallins in diabetic lenses. Invest Ophthalmol Vis Sci. 2002:43(10):3265-72

8. Horwitz J. Alpha-crystallin. Exp Eye Res. 2003;76(2):145-53. 
9. Zhou P, LU Y, Sun XH. Effects of a novel DNA methyltransferase inhibitor Zebularine on human lens epithelial cells. Mol Vis. 2012;18:22-8.

10. Zhou P, Lu Y, Sun XH. Zebularine suppresses TGF-beta-induced lens epithelial cell-myofibroblast transdifferentiation by inhibiting MeCP2. Mol Vis. 2011;17:2717-23.

11. Zhou P, Luo Y, Liu X, Fan L, Lu Y. Down-regulation and CpG island hypermethylation of CRYAA in age-related nuclear cataract. FASEB J. 2012;26(12):4897-902.

12. Shannon K, Armstrong SA. Genetics, epigenetics, and leukemia. N Engl J Med. 2010;363(25):2460-1.

13. Cvekl A, Mitton KP. Epigenetic regulatory mechanisms in vertebrate eye development and disease. Heredity. 2010;105(1):135-51.

14. Boyes J, Bird A. DNA methylation inhibits transcription indirectly via a methyl-CpG binding protein. Cell. 1991;64(6):1123-34.

15. Yu KD, Di GH, Fan L, Wu J, Hu Z, Shen ZZ, Huang W, Shao ZM. A functional polymorphism in the promoter region of GSTM1 implies a complex role for GSTM1 in breast cancer. FASEB J. 2009;23(7):2274-87.

16. Zhu WG, Srinivasan K, Dai Z, Duan W, Druhan LJ, Ding H, Yee L, Villalona-Calero MA, Plass C, Otterson GA. Methylation of adjacent CpG sites affects Sp1/Sp3 binding and activity in the p21(Cip1) promoter. Mol Cell Biol. 2003;23(12):4056-65.

17. Dong W, Wang L, Chen X, Sun P, Wu Y. Upregulation and CpG island hypomethylation of the TRF2 gene in human gastric cancer. Dig Dis Sci. 2010;55(4):997-1003.

18. Zhang S, Yu N, Zhang R, Zhang S, Wu J. Interleukin-17A induces IL-1 beta secretion from RPE cells Via the NLRP3 inflammasome. Invest Ophthalmol Vis Sci. 2016;57(2):312-9.

19. Niu L, Zhang S, Wu J, Chen L, Wang Y. Upregulation of NLRP3 inflammasome in the tears and ocular surface of Dry Eye patients. PLoS One. 2015;10(5):e0126277.

20. Mao W, Rubin JS, Anoruo N, Wordinger RJ, Clark AF. SFRP1 promoter methylation and expression in human trabecular meshwork cells. Exp Eye Res. 2012;97(1):130-6.

21. Hunter A, Spechler PA, Cwanger A, Song Y, Zhang Z, Ying GS, Hunter AK, Dezoeten E, Dunaief JL. DNA methylation is associated with altered gene expression in AMD. Invest Ophthalmol Vis Sci. 2012;53(4):2089-105.

22. McCarthy N. Retinoblastoma: epigenetic outcome. Nat Rev Cancer. 2012;12(2):80.

23. Joseph B, Mamatha G, Raman G, Shanmugam MP, Kumaramanickavel G. Methylation status of RB1 promoter in Indian retinoblastoma patients. Cancer Biol Ther. 2004;3(2):184-7.

24. Cohen Y, Merhavi-Shoham E, Avraham RB, Frenkel S, Pe'er J, Goldenberg-Cohen N. Hypermethylation of CpG island loci of multiple tumor suppressor genes in retinoblastoma. Exp Eye Res. 2008;86(2):201-6.

25. Choy KW, Pang CP, Fan DS, Lee TC, Wang JH, Abramson DH, Lo KW, To KF, Yu CB, Beaverson KL, et al. Microsatellite instability and MLH1 promoter methylation in human retinoblastoma. Invest Ophthalmol Vis Sci. 2004;45(10):3404-9.

26. Maat W, Beiboer SH, Jager MJ, Luyten GP, Gruis NA, van der Velden PA. Epigenetic regulation identifies RASEF as a tumor-suppressor gene in uveal melanoma. Invest Ophthalmol Vis Sci. 2008:49(4):1291-8.

27. van der Velden PA, Metzelaar-Blok JA, Bergman W, Monique $H$, Hurks $H$, Frants RR, Gruis NA, Jager MJ. Promoter hypermethylation: a common cause of reduced p16(INK4a) expression in uveal melanoma. Cancer Res. 2001:61(13):5303-6.

28. Radosevich M, Jager M, Ono SJ. Inhibition of MHC class II gene expression in uveal melanoma cells is due to methylation of the CIITA gene or an upstream activator. Exp Mol Pathol. 2007;82(1):68-76.

29. Zeschnigk M, Tschentscher F, Lich C, Brandt B, Horsthemke B, Lohmann DR. Methylation analysis of several tumour suppressor genes shows a low frequency of methylation of CDKN2A and RARB in uveal melanomas. Comp Funct Genomics. 2003;4(3):329-36.

30. Palsamy P, Ayaki M, Elanchezhian R, Shinohara T. Promoter demethylation of Keap1 gene in human diabetic cataractous lenses. Biochem Biophys Res Commun. 2012;423(3):542-8.

31. Zhu XJ, Zhou P, Zhang KK, Yang J, Luo Y, Lu Y. Epigenetic regulation of alphaA-crystallin in high myopia-induced dark nuclear cataract. PLoS One. 2013;8(12):e81900.

32. Zhu XJ, Zhang KK, Zhou P, Jiang CH, Lu Y. alphaA-crystallin gene CpG islands hypermethylation in nuclear cataract after pars plana vitrectomy. Graefes Arch Clin Exp Ophthalmol. 2015;253(7):1043-51.
33. Palsamy P, Bidasee KR, Ayaki M, Augusteyn RC, Chan JY, Shinohara T. Methylglyoxal induces endoplasmic reticulum stress and DNA demethylation in the Keap1 promoter of human lens epithelial cells and age-related cataracts. Free Radic Biol Med. 2014:72:134-48.

34. Palsamy P, Bidasee KR, Shinohara T. Selenite cataracts: activation of endoplasmic reticulum stress and loss of Nrf2/Keap1-dependent stress protection. Biochim Biophys Acta. 2014;1842(9):1794-805.

35. Li F, Wang Y, Zhang G, Zhou J, Yang L, Guan H. Expression and methylation of DNA repair genes in lens epithelium cells of age-related cataract. Mutat Res. 2014;766-767:31-6.

36. Osterod M, Hollenbach S, Hengstler JG, Barnes DE, Lindahl T, Epe B. Age-related and tissue-specific accumulation of oxidative DNA base damage in 7,8-dihydro-8-oxoguanine-DNA glycosylase (Ogg1) deficient mice. Carcinogenesis. 2001;22(9):1459-63.

37. Sorte K, Sune P, Bhake A, Shivkumar VB, Gangane N, Basak A. Quantitative assessment of DNA damage directly in lens epithelial cells from senile cataract patients. Mol Vis. 2011;17:1-6.

38. Wang Y, Li F, Zhang G, Kang L, Qin B, Guan H. Altered DNA methylation and expression profiles of 8-oxoguanine DNA glycosylase 1 in lens tissue from Age-related cataract patients. Curr Eye Res. 2015;40(8):815-21.

39. Ye H, Jiang $Y$, Jing $Q$, Li D, Maimaiti T, Kasimu D, Lu Y. LOXL1 hypermethylation in pseudoexfoliation syndrome in the Uighur population. Invest Ophthalmol Vis Sci. 2015;56(10):5838-43.

40. Bird A. DNA methylation patterns and epigenetic memory. Genes Dev. 2002;16(1):6-21.

41. Clark SJ, Harrison J, Molloy PL. Sp1 binding is inhibited by $(m) C p(m) C p G$ methylation. Gene. 1997;195(1):67-71

42. Zelko IN, Mueller MR, Folz RJ. CpG methylation attenuates Sp1 and Sp3 binding to the human extracellular superoxide dismutase promoter and regulates its cell-specific expression. Free Radic Biol Med. 2010;48(7):895-904.

43. Douet V, Heller MB, Le Saux O. DNA methylation and Sp1 binding determine the tissue-specific transcriptional activity of the mouse Abcc6 promoter. Biochem Biophys Res Commun. 2007;354(1):66-71.

44. Li D, Da L, Tang H, Li T, Zhao M. CpG methylation plays a vital role in determining tissue- and cell-specific expression of the human cell-deathinducing DFF45-like effector A gene through the regulation of Sp1/Sp3 binding. Nucleic Acids Res. 2008:36(1):330-41.

45. Guo D, Wu B, Yan J, Li X, Sun H, Zhou D. A possible gene silencing mechanism: hypermethylation of the Keap1 promoter abrogates binding of the transcription factor Sp1 in lung cancer cells. Biochem Biophys Res Commun. 2012;428(1):80-5.

\section{Submit your next manuscript to BioMed Central} and we will help you at every step:

- We accept pre-submission inquiries

- Our selector tool helps you to find the most relevant journal

- We provide round the clock customer support

- Convenient online submission

- Thorough peer review

- Inclusion in PubMed and all major indexing services

- Maximum visibility for your research

Submit your manuscript at www biomedcentral.com/submit
C) Biomed Central 